\title{
Direct Reuse of Rare Earth Permanent Magnets-Coating Integrity
}

Høgberg, Stig; Holbøll, Joachim; Mijatovic, Nenad; Jensen, Bogi Bech; Bendixen, Flemming Buus

Published in:

IEEE Transactions on Magnetics

Link to article, DOI:

10.1109/TMAG.2016.2636804

Publication date:

2017

Document Version

Peer reviewed version

Link back to DTU Orbit

Citation (APA):

Høgberg, S., Holbøll, J., Mijatovic, N., Jensen, B. B., \& Bendixen, F. B. (2017). Direct Reuse of Rare Earth Permanent Magnets-Coating Integrity. IEEE Transactions on Magnetics, 53(4), [8000609].

https://doi.org/10.1109/TMAG.2016.2636804

\section{General rights}

Copyright and moral rights for the publications made accessible in the public portal are retained by the authors and/or other copyright owners and it is a condition of accessing publications that users recognise and abide by the legal requirements associated with these rights.

- Users may download and print one copy of any publication from the public portal for the purpose of private study or research.

- You may not further distribute the material or use it for any profit-making activity or commercial gain

- You may freely distribute the URL identifying the publication in the public portal 


\title{
Direct Reuse of Rare Earth Permanent Magnets - Coating Integrity
}

\author{
Stig Högberg ${ }^{1}$, Member, IEEE, Joachim Holbøl1 ${ }^{1}$, Senior Member, IEEE, \\ Nenad Mijatovic ${ }^{1}$, Member, IEEE, Bogi Bech Jensen ${ }^{2}$, Senior Member, IEEE, \\ and Flemming Buus Bendixen ${ }^{3}$, Member, IEEE, \\ ${ }^{1}$ Department of Electrical Engineering, Technical University of Denmark \\ ${ }^{2}$ Glasir, Torshavn College, Faroe Islands \\ ${ }^{3}$ Sintex a/s, Jyllandsvej 14, 9500 Hobro, Denmark
}

\begin{abstract}
Rare earth permanent magnets can be reused directly as an alternative to traditional recycling methods, in which scrapped magnets are re-processed into new magnets by undergoing many of the original energy-intensive and expensive production processes. Direct reuse entails using segmented magnet assemblies built by several small standard-sized magnets that can be reused directly in a number of different applications. A central part of the direct reuse strategy is to separate and demagnetize magnets by heating them to the Curie temperature.

We investigated the validity of direct reuse as a rare earth magnet recycling strategy by evaluating the extent to which the heat-driven demagnetization cycles affected magnetic properties, as well as the integrity of the protective coating of $\mathrm{Nd}-\mathrm{Fe}-\mathrm{B}$ magnets. The experimental investigation consisted of four different tests, and was applied to 300 magnets that had either been heated once, five times, or none at all. The tests included J-H measurements, coating pull-off test, corrosion salt spray test, and optical microscopy of the interface between coating and magnet. Magnets coated with $\mathrm{Zn}$, Epoxy, $\mathrm{Ni}-\mathrm{Cu}-\mathrm{Ni}$, and $\mathrm{Ni}-\mathrm{Cu}+\mathrm{Epoxy}$ were investigated, of which $\mathrm{Ni}-\mathrm{Cu}+$ Epoxy showed no degradation after heat treatment. Direct reuse as a recycling strategy could therefore be a valuable alternative to traditional recycling.
\end{abstract}

Index Terms-Direct drive wind turbine generator, direct reuse, experimental verification, finite element analysis, recycling REPM.

\section{INTRODUCTION}

D IRECT reuse of rare earth permanent magnets (REPM) is a recycling strategy that differs significantly from other strategies by not producing new magnets from scrapped ones. Instead, as the name indicates, magnets are reused in their original shape and size. Direct reuse is the least investigated method for recycling REPMs, but it is potentially very promising.

Various recycling strategies for REPM have already been presented. The available published literature was discussed in a literature review from 2013 covering recycling of rare earths (not just permanent magnets) [? ]. The topic was split into five recycling methods: gas-phase extraction, pyrometallurgical methods, hydrometallurgical methods, reprocessing

Manuscript received May 30, 2016. Corresponding author: Stig Högberg (email: stigho@elektro.dtu.dk). This work was supported by the Danish Ministry of Science, Innovation and Higher Education through the REEgain project of alloys of hydrogen decrepitation, and direct ruse in current form/shape. All methods aside from direct reuse are challenged either by environmental aspects because of a high consumption of chemicals or vast generation of waste water, high energy consumption, many process steps, or the method has limited reach and cannot handle mixed compositional variations. Direct reuse is claimed to have two disadvantages: 1) that it is only applicable for large, easily accessible magnets from e.g. wind turbine generators, large electric motors and generators in hybrid and electric vehicles, and 2) that magnets from these applications are not available in large quantities today.

An important advantage of the direct reuse method over the others is that the magnetic properties of the recycled magnets are unchanged by the recycling process. This has to date for non-direct reuse strategies only been possible if raw rare earth material is added in order to compensate the inevitable loss [110]. A detailed summary of 10 recycling studies from 2004 2014 that were based on one of the four other method is given in Table I. The summary underlines the difficulty of achieving similar magnetic performance of recycled REPM using without adding new raw material.

In [11], we proposed to construct magnet poles from several small standard-sized magnets, since each of the small magnets can be reused directly in constructing a new pole. Average output power, cogging torque, and torque ripple of a $3 \mathrm{MW}$ direct drive wind turbine generator was simulated in a 2-D finite element environment. An illustration of the solid bread loaf shaped magnet compared the a segmented design is shown in Figure 1. The simulated performance of the two was equal between when applying pole-shaping to the segmented design to control the cogging torque and torque ripple.

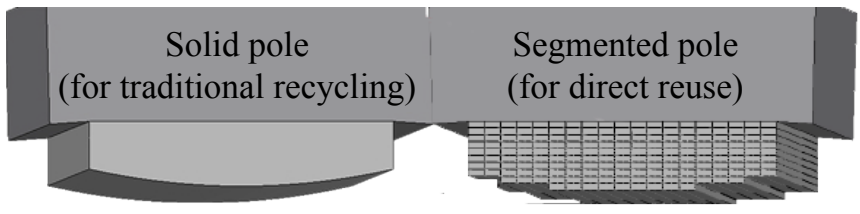

Fig. 1. Comparison of a pole-section from a 110 pole wind turbine generator with solid bread loaf shaped magnets (left) and direct reuse friendly segmented magnets (right). This concept was investigated in [11].

In fact, it was possible to improve both cogging torque and torque ripple by shifting some of the small magnets. A small 
TABLE I

OVERVIEW OF RECYCLING RESULTS FROM VARIOUS RESEARCHERS. THE ORIGINAL MAGNET CHARACTERISTICS (REMANENCE FLUX DENSITY, $B_{r}$, COERCIVITY, $H_{c}$, AND MAXIMUM ENERGY PRODUCT, $(B H)_{\max }$ ) ON WHICH RECYCLING IS PERFORMED IS LISTED TO THE LEFT, WHEREAS THE RESULTING MAGNET CHARACTERISTICS ARE SHOWN TO THE RIGHT. WHETHER AN ADDITIVE IS USED IN THE PROCESS AND FOCUS OF THE RESEARCH ARE ALSO SHOWN.

\begin{tabular}{|c|c|c|c|c|}
\hline Source & Starting material & Recycled material & Unit & Added material \\
\hline \multirow{4}{*}{$\begin{array}{r}\text { Li et al. [1] } \\
\text { [2014] }\end{array}$} & Sintered N35H & Sintered Nd-Fe-B & & \multirow{4}{*}{$\begin{array}{c}2.0 \text { wt. } \% \\
\text { Dy-rich alloy }\end{array}$} \\
\hline & $=1.22$ & $(\downarrow \quad 2.46 \%)$ & $T$ & \\
\hline & $\left|H_{c i}\right|=1353$ & $=1250.0(\downarrow \quad 7.61 \%)$ & $k A \cdot m^{-1}$ & \\
\hline & $(\mathrm{BH})_{\max }=289.2$ & $(\mathrm{BH})_{\max }=267.4 \quad(\downarrow \quad 7.54 \%)$ & $k J \cdot m^{-3}$ & \\
\hline \multirow{4}{*}{ Sheridan et al. [2] } & Sintered Nd-Fe-B & Sintered Nd-Fe-B: composition 1 & & \multirow{8}{*}{ none } \\
\hline & $B_{r} \quad=1.36$ & $B_{r} \quad=1.08 \quad(\downarrow 20.59 \%)$ & $T$ & \\
\hline & $\left|H_{c i}\right|=860.0$ & $\left|H_{c i}\right|=840.0 \quad(\downarrow \quad 2.33 \%)$ & $k A \cdot m^{-1}$ & \\
\hline & $(\mathrm{BH})_{\max }=340.0$ & $(\mathrm{BH})_{\max }=175.0 \quad(\downarrow 48.53 \%)$ & $k J \cdot m^{-3}$ & \\
\hline \multirow[t]{4}{*}[2014]{} & Sintered Nd-Fe-B & Sintered Nd-Fe-B: composition 2 & & \\
\hline & $B_{r} \quad=1.10$ & $B_{r} \quad=0.94 \quad(\downarrow 14.55 \%)$ & $T$ & \\
\hline & $\left|H_{c i}\right|=1450.0$ & $=740.0 \quad(\downarrow \quad 48.97 \%)$ & $k A \cdot m^{-1}$ & \\
\hline & $(\mathrm{BH})_{\max }=230.0$ & $(\mathrm{BH})_{\max } \approx 117.0 \quad(\downarrow 49.13 \%)$ & $k J \cdot m^{-3}$ & \\
\hline \multirow[b]{4}{*}{ Chinnasamy et al. [3] } & Sintered Nd-Fe-B & Sintered Nd-Fe-B & & \multirow{4}{*}{ virgin elements $<10 \%$} \\
\hline & $B_{r} \quad=1.27$ & $B_{r} \quad=1.17 \quad(\downarrow \quad 7.87 \%)$ & $T$ & \\
\hline & $\left|H_{c i}\right|=1246.6$ & $\left|H_{c i}\right|=1141.9(\downarrow \quad 8.40 \%)$ & $k A \cdot m^{-1}$ & \\
\hline & $(\mathrm{BH})_{\max }=289.5$ & $(\mathrm{BH})_{\max }=254.6 \quad(\downarrow 12.06 \%)$ & $k J \cdot m^{-3}$ & \\
\hline \multirow[t]{4}{*}{ [2013] } & Sm-Co scrap & Sintered Sm-Co & & \\
\hline & $B_{r} \quad=\mathrm{n} / \mathrm{a}$ & $B_{r} \quad=1.07$ & $T$ & \\
\hline & $\left|H_{c i}\right|=\mathrm{n} / \mathrm{a}$ & $=1949.6$ & $k A \cdot m^{-1}$ & \\
\hline & $(\mathrm{BH})_{\max }=\mathrm{n} / \mathrm{a}$ & $(\mathrm{BH})_{\max }=215.7$ & $k J \cdot m^{-3}$ & \\
\hline \multirow{8}{*}{$\begin{array}{r}\text { Gutfleisch et al. [4] } \\
\text { [2013] }\end{array}$} & Sintered Nd-Fe-B & Anisotropic Nd-Fe-B powder & & \multirow{8}{*}{ none } \\
\hline & $B_{r} \quad=1.42$ & $B_{r} \quad=1.26 \quad(\downarrow 11.27 \%)$ & $T$ & \\
\hline & $\left|H_{c i}\right|=1130.0$ & $\left|H_{c i}\right|=1225.5(\uparrow \quad 8.45 \%)$ & $k A \cdot m^{-1}$ & \\
\hline & $(\mathrm{BH})_{\max }=\mathrm{n} / \mathrm{a}$ & $(\mathrm{BH})_{\max }=255.0$ & $k J \cdot m^{-3}$ & \\
\hline & Sintered Nd-Fe-B & Anisotropic Nd-Fe-B powder & & \\
\hline & $B_{r} \quad=1.13$ & $B_{r} \quad=0.91 \quad(\downarrow 19.47 \%)$ & $T$ & \\
\hline & $=2793.2$ & $=1193.7(\downarrow \quad 57.26 \%)$ & $k A \cdot m^{-1}$ & \\
\hline & $(\mathrm{BH})_{\max }=\mathrm{n} / \mathrm{a}$ & $(\mathrm{BH})_{\max }=140.0$ & $k J \cdot m^{-3}$ & \\
\hline \multirow{5}{*}{$\begin{array}{r}\text { Sheridan et al. [5] } \\
\text { [2012] }\end{array}$} & \multirow{4}{*}{$\begin{array}{l}\text { Sintered Nd-Fe-B } \\
B_{r}=1.36 \\
\left|H_{c i}\right|=860.0 \\
(\mathrm{BH})_{\max }=340.0\end{array}$} & Anisotropic Nd-Fe-B powder & \multirow{4}{*}{$\begin{array}{c}T \\
k A \cdot m^{-1} \\
k J \cdot m^{-3}\end{array}$} & \multirow{4}{*}{ none } \\
\hline & & $(\downarrow \quad 19.12 \%)$ & & \\
\hline & & $=800.0 \quad(\downarrow \quad 6.98 \%)$ & & \\
\hline & & $(\mathrm{BH})_{\max }=123.0 \quad(\downarrow \quad 63.82 \%)$ & & \\
\hline & Sintered N42 Nd-Fe-B & Bonded Nd-Fe-B & & \multirow{4}{*}{ none } \\
\hline \multirow{3}{*}{$\begin{array}{r}\text { Perigo et al. [6] } \\
\text { [2012] }\end{array}$} & $=1.29$ & $=0.58 \quad(\downarrow \quad 55.04 \%)$ & $T$ & \\
\hline & $\left|H_{c i}\right|=978.8$ & $=915.1 \quad(\downarrow \quad 6.51 \%)$ & $k A \cdot m^{-1}$ & \\
\hline & $(\mathrm{BH})_{\max }=\mathrm{n} / \mathrm{a}$ & $(\mathrm{BH})_{\max }=50.0$ & $k J \cdot m^{-3}$ & \\
\hline \multirow{8}{*}{$\begin{array}{r}\text { Zakotnik et al. [7] } \\
\text { [2009] }\end{array}$} & Sintered Nd-Fe-B & Sintered Nd-Fe-B: 1st cycle & & \multirow{8}{*}{$\begin{array}{l}\text { Nd hydride } \\
1 \% \text { per cycle }\end{array}$} \\
\hline & $=1.18$ & $=1.18 \quad(\downarrow \quad 0.00 \%)$ & $T$ & \\
\hline & $\left|H_{c i}\right|=870.0$ & $\left|H_{c i}\right|=695.0 \quad(\downarrow 20.11 \%)$ & $k A \cdot m^{-1}$ & \\
\hline & $(\mathrm{BH})_{\max }=260.0$ & $(\mathrm{BH})_{\max }=260.0 \quad(\downarrow \quad 0.00 \%)$ & $k J \cdot m^{-3}$ & \\
\hline & Sintered Nd-Fe-B & Sintered Nd-Fe-B: 4th cycle & & \\
\hline & $=1.18$ & $\approx 1.18 \quad(\downarrow \quad 0.00 \%)$ & $T$ & \\
\hline & $\left|H_{c i}\right|=870.0$ & $\left|H_{c i}\right| \quad \approx 830.0 \quad(\downarrow \quad 4.60 \%)$ & $k A \cdot m^{-1}$ & \\
\hline & $(\mathrm{BH})_{\max }=260.0$ & $(\mathrm{BH})_{\max } \approx 260.0 \quad(\downarrow \quad 0.00 \%)$ & $k J \cdot m^{-3}$ & \\
\hline & & CONTINUES & & \\
\hline
\end{tabular}


TABLE I CONTINUED

\begin{tabular}{|c|c|c|c|c|c|}
\hline Source & Starting material & Recycled material & & Unit & Added material \\
\hline $\begin{array}{r}\text { Zakotnik et al. [8] } \\
\text { [2008] }\end{array}$ & $\begin{array}{l}\text { Sintered Nd-Fe-B } \\
B_{r}=1.32 \\
\left|H_{c i}\right|=960 \\
(\mathrm{BH})_{\max }=325\end{array}$ & $\begin{array}{l}\text { Sintered Nd-Fe-B } \\
\begin{array}{ll}B_{r} & =1.24 \\
\left|H_{c i}\right| & =830 \\
(\mathrm{BH})_{\max } & =290\end{array}\end{array}$ & 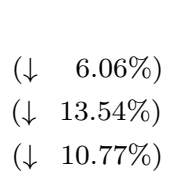 & $\begin{array}{c}T \\
k A \cdot m^{-1} \\
k J \cdot m^{-3}\end{array}$ & not discussed \\
\hline $\begin{array}{r}\text { Kim et al. [10] } \\
{[2004]}\end{array}$ & $\begin{array}{l}\text { Sintered Nd-Fe-B } \\
B_{r} \approx 1.25 \\
\left|H_{c i}\right| \approx 1010 \\
(\mathrm{BH})_{\max }=\mathrm{n} / \mathrm{a}\end{array}$ & $\begin{array}{l}\text { Anisotropic Nd-Fe- } \\
B_{r}=1.16 \\
\left|H_{c i}\right|=1058 \\
(\mathrm{BH})_{\max }=249.1\end{array}$ & $\begin{array}{l}\text { powder } \\
\left(\begin{array}{ll}\downarrow & 7.20 \%) \\
(\uparrow & 4.75 \%)\end{array}\right.\end{array}$ & $\begin{array}{c}T \\
k A \cdot m^{-1} \\
k J \cdot m^{-3}\end{array}$ & $\mathrm{DyF}_{3}(\approx 5 \%)$ \\
\hline $\begin{array}{r}\text { Itoh et al. [9] } \\
\text { [2004] }\end{array}$ & $\begin{array}{l}\text { Sintered Nd-Fe-B } \\
B_{r}=\mathrm{n} / \mathrm{a} \\
\left|H_{c i}\right|=\mathrm{n} / \mathrm{a} \\
(\mathrm{BH})_{\max }=\mathrm{n} / \mathrm{a}\end{array}$ & $\begin{array}{l}\text { Bonded Nd-Fe-B } \\
B_{r} \quad=0.69 \\
\left|H_{c i}\right|=700 \\
(\mathrm{BH})_{\max }=71.0\end{array}$ & & $\begin{array}{c}T \\
k A \cdot m^{-1} \\
k J \cdot m^{-3}\end{array}$ & not discussed \\
\hline
\end{tabular}

length increase of maximum $3.5 \%$ was needed to compensate for the extra air-gaps between each small magnet, as well as the lower cross-sectional area of the segmented pole. Thus, aside from the usual benefits from magnet segmentation, such as reduced eddy-current loss, ease of assembly, and improving torque characteristics, it can also allow for direct reuse as a recycling strategy of REPM. Figure 2 illustrates the steps included in the reuse strategy starting with standard magnets in applications.

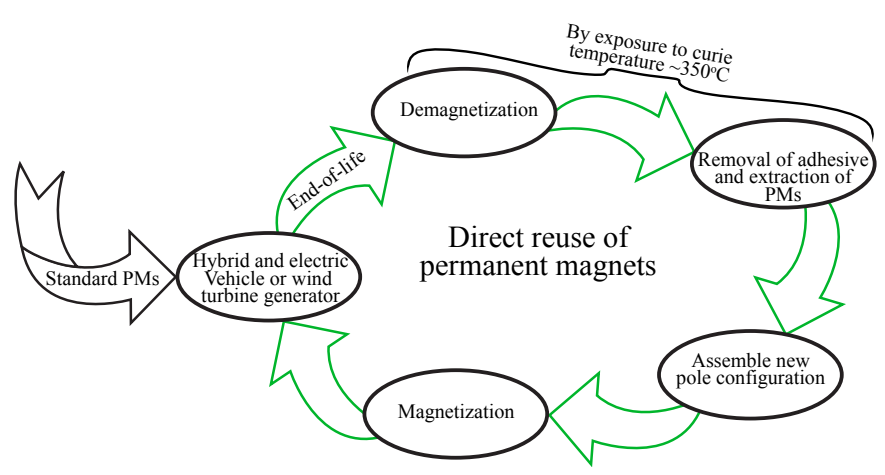

Fig. 2. Schematic representation of the reuse strategy.

In this article we expand on the previously published study by investigating to which extent the heat-driven demagnetization cycles can demagnetize Nd-Fe-B magnets without affecting their magnetic properties or the integrity of the protective coating. It is vital to the recycling strategy that the performance of both remain unchanged after recycling. This article is based on the experimental study of 300 non-magnetized sintered Nd-Fe-B magnets of four different commercially available coatings: Epoxy, Ni-Cu-Ni, Ni-Cu+Epoxy, and $\mathrm{Zn}$, which were selected because they are believed to represent different very different ends of the commercially available coatings. However, many potentially good coatings were deselected for this study as a consequence of the extensive tests applied to each magnet as will be clear throughout this article.

\section{A. Sample preparation}

For each of the four coatings, one third of the magnets were left untreated and used as reference magnets in the tests, one third received 1 cycle of the Curie temperature, and the last third received 5 cycles of the Curie temperature. Thereby achieving one batch of original magnets, one batch of magnets recycled once, and one batch recycled five times. The magnets are depicted in Figure 3, where the oven with nitrogen flow is also shown. The nitrogen protects the magnets and coatings from oxidizing at the high temperature.

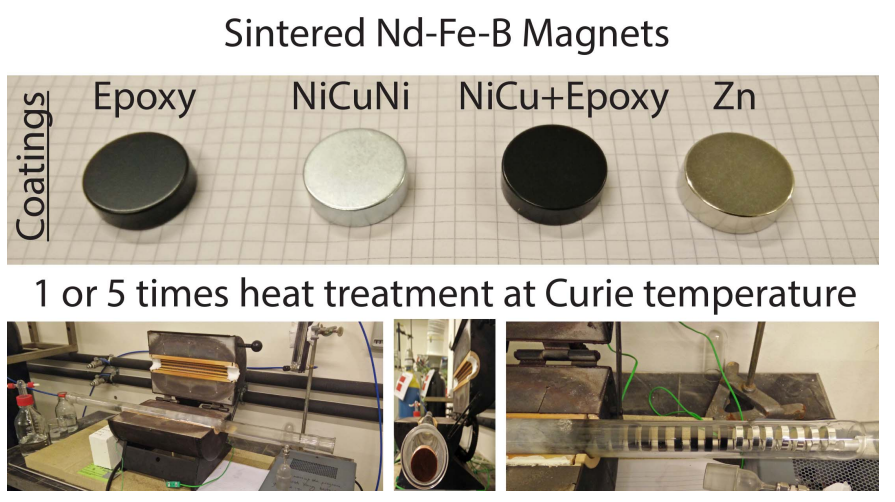

Fig. 3. Top: Test magnets with four different protective coatings. Bottom left: Oven used to heat the magnets to the Curie temperature of approximately $350^{\circ} \mathrm{C}$ under a protective atmosphere of nitrogen. Bottom middle and right: A batch of magnets inserted into the oven for heating.

\section{Methodology}

The investigation of the recycled magnets include four parts: J-H measurements, coating pull-off test, corrosion test in salt spray chamber, and finally optical microscopy of coating/magnet interface. A brief description of each of these is given in the following:

\section{A. J-H measurements}

Reference, 1 cycle, and 5 cycled magnets were magnetized by a pulsed field strong enough to saturate them, and their 
second quadrant $\mathrm{J}-\mathrm{H}$ characteristics was measured using a Brockhaus Messtechnik HG 200. An example of the characteristic is depicted in Figure 4 in which $\mathrm{J}-\mathrm{H}$ and $\mathrm{B}-\mathrm{H}$ curves are shown together with the $0.5 B_{r}$ and $0.9 B_{r}$ lines for calculating the maximum energy product and the squareness factor, respectively.

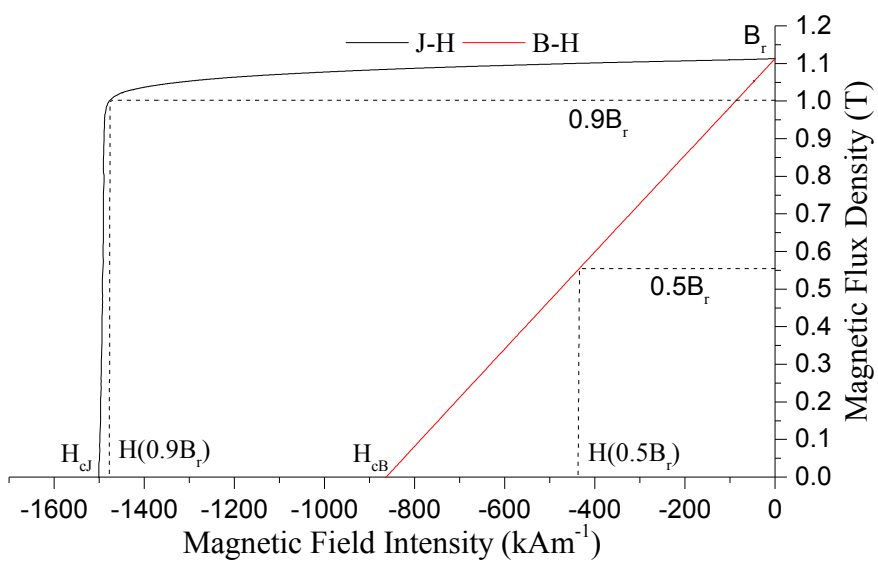

Fig. 4. J-H and $\mathrm{B}-\mathrm{H}$ curve for a $\mathrm{Ni}-\mathrm{Cu}+$ Epoxy coated reference magnet. Also showing the $0.5 B_{r}$ and $0.9 B_{r}$ lines for calculating the maximum energy product and the squareness factor, respectively.

\section{B. Coating pull-off test}

An aluminum piece (dolly) was glued to the coating on each side of the magnets, as depicted in Figure 5, and later pulled off using a PosiTest AT-A Automatic adhesion tester that provides the pressure at which pull-off happens. Its traceable load cell offers $\pm 1 \%$ accuracy.

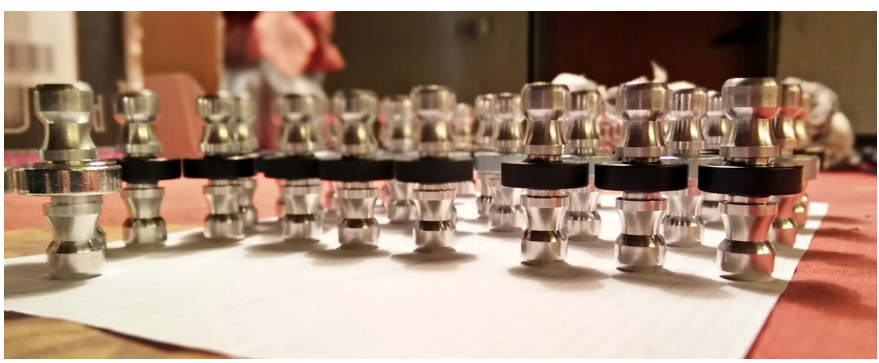

Fig. 5. Magnets prepared for coating pull-off test. An aluminum piece on each side of the magnets is glued to the coating.

\section{Corrosion test in salt spray chamber}

Test magnets were placed in a salt spray chamber as Figure 6 depicts, and their level of corrosion was monitored over time and evaluated in accordance with DS/EN ISO 46283 standard. Table II translates the ISO scale to the visible amount of rust. When more than $50 \%$ of the test-surface of a magnet is covered in rust it is removed from the test.

\section{Optical microscopy of coating/magnet interface}

Magnets were cast into support structures, and cut in order to investigate the interface between coating and magnet for
TABLE II

ISO RUST LEVELS AND THEIR TRANSLATION IN PERCENTAGE IN ACCORDANCE WITH DS/EN ISO 4628-3.

\begin{tabular}{ccccccc}
\hline ISO level & 0 & 1 & 2 & 3 & 4 & 5 \\
\hline Visual rust & $0 \%$ & $0.05 \%$ & $0.5 \%$ & $1 \%$ & $8 \%$ & $40-50 \%$ \\
\hline
\end{tabular}
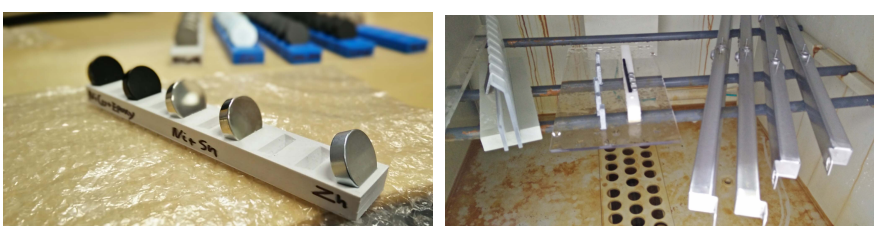

Fig. 6. Left: Magnets prepared for salt spray test. Right: Salt spray chamber.

defects and changes caused by the heat treatments. The magnets in support material as well as the Carl Zeiss Axiovert 200 light optical microscope (LOM) are depicted in Figure 7. LOM investigation was chosen for its excellent magnification, which made possible the visual investigation of the entire border between magnet and coating. Scanning electron microscopy (SEM) is another known method to conduct such investigation. It offers greater magnification and also information on the chemical composition of the samples. However, SEM is especially ideal for very detailed domain investigations, but in this project it was not cost-effective to perform SEM on the entire border between magnet and coating for all the samples.
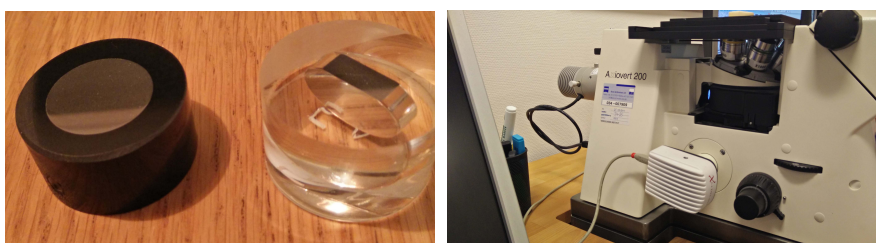

Fig. 7. Left: Magnets cast into support structure. Right: Carl Zeiss Axiovert 200 light optical microscope.

\section{RESULTS}

The results from the four tests will be presented in this section one test at a time. All magnet batches except one received their intended heat-treatment; the batch of epoxy coated magnets that were supposed to receive 1 cycle of Curie temperature instead received 1 cycle of approximately $650^{\circ} \mathrm{C}$ owing to a faulty thermocouple. In the interest of transparency and full disclosure, we chose to include the results for 1-cycle epoxy even though they are not be considered accurate within the framework of the experiment. However, comparing them to the 5-cycles epoxy, knowing that these were exposed to a temperature much higher than the Curie temperature, will still provide valuable information about the recycling strategy.

\section{A. J-H measurements}

The following magnet characteristics were measured and plotted in Figure 8 (from the top): Remanence flux density, intrinsic coercivity, maximum energy product, and squareness 


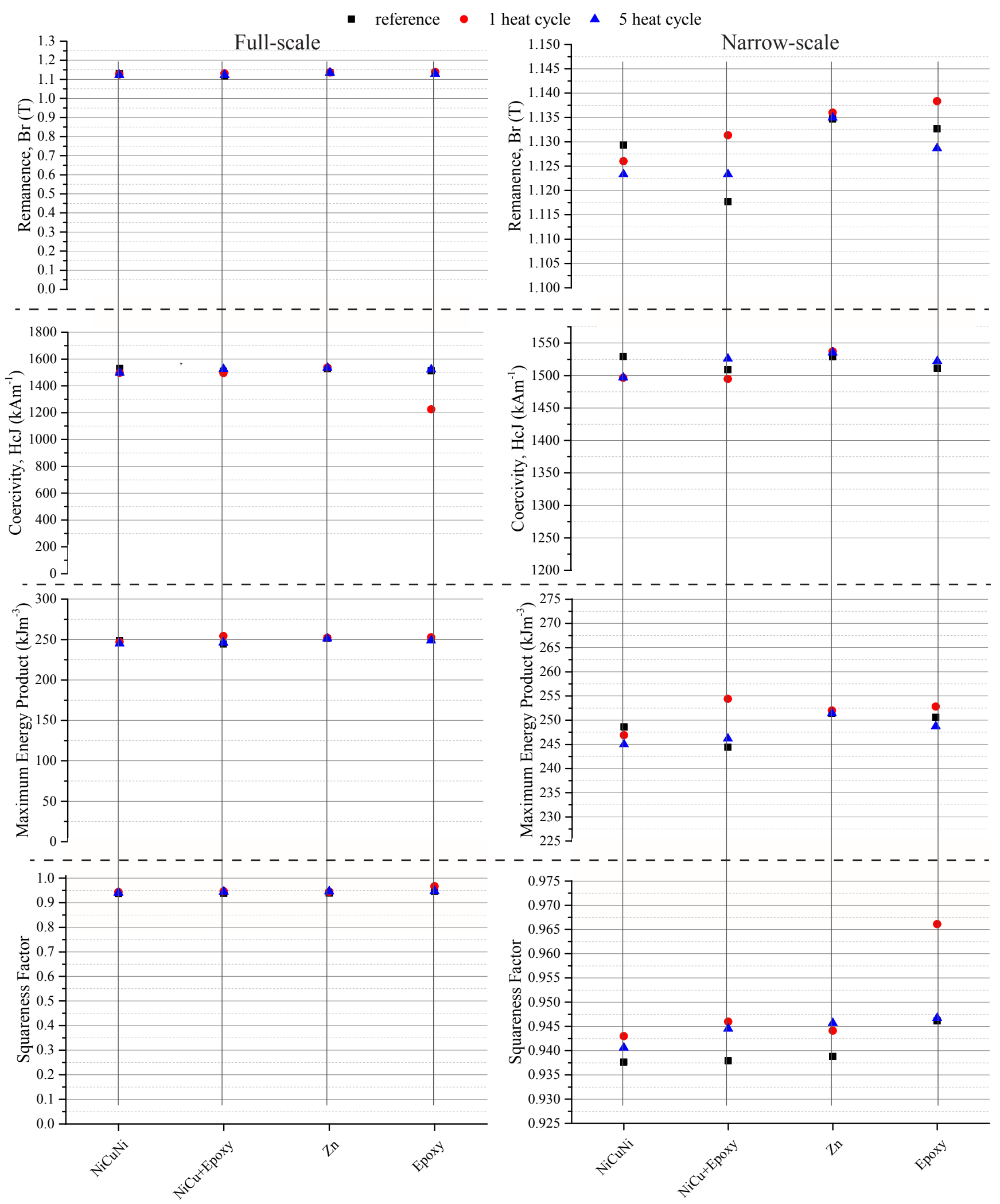

Fig. 8. Magnet characteristics as a function of coating type (from the top): Remanence flux density, $\mathrm{Br}$, intrinsic coercivity, $H_{c J}$, maximum energy product, and squareness factor. A narrowly scaled plot is shown to the right of the full-scale plot for details.

factor. A data point displayed in the following graphs represent an average of three measurements performed on three individual magnets that all underwent the same treatment.
As Figure 8 depicts, the remanence flux density is unchanged through the heat cycles, and are equal to that of the reference. 
All heat treated magnets show similar magnetic performance as compared to the reference batch regardless of the coating. That is, all except the 1-cycle epoxy batch that were exposed a much higher temperature. The intrinsic coercivity of 1-cycle epoxy is $20 \%$ lower than the rest. This is likely due to a micro structural change caused by the high temperature, which in turn have compromised the coercivity. All other magnets maintained their coercivity at levels equal to those of the references.

The intrinsic coercivity does not influence the maximum energy product calculation, which resultet in a value close to $250 \mathrm{~kJ} \cdot \mathrm{m}^{-3}$ for all the magnets, including 1-cycle epoxy.

Another magnet quality figure-of-merit is squareness factor, sq, calculated with reference to Figure 4 by Equation 1

$$
s q=\frac{H\left(0.9 \cdot B_{r}\right)}{H_{c J}}
$$

Where $\mathrm{H}\left(0.9 \cdot \mathrm{B}_{r}\right)$ is the magnetic field intensity when flux density is equal to $90 \%$ of $\mathrm{B}_{r}$, and $\mathrm{H}_{c J}$ is the coercivity.

The closer this number is to one the better the magnet. Said in other words, the slope of J-H before the knee-point should be as flat as possible. The last plot in Figure 8 depicts the squareness factor, which remained unchanged for all the magnets regardless of the number of heat cycles.

The results suggest that not 1 nor 5 cycles of heat treatment affects the magnetic properties of the Nd-Fe-B magnets in any significant way.

\section{B. Coating pull-off test}

Unlike the results presented for the J-H measurements, the pull-off strength vary between the different type of coatings as depicted in Figure 9. None of the coatings show a clear degradation as a function of heat cycles. The $\mathrm{Zn}$ coating does indicate a drop already after the first heat cycle, which is not worsened by 5 cycles. However, the Ni-Cu-Ni coating is slightly better attached to the magnet after the heat treatments, which could mean that the Ni-layer connects better with the magnet due to the high temperature. This is, however, unlikely since the melting temperature of $\mathrm{Ni}$ is $1455^{\circ} \mathrm{C}$, and since a similar trend would be expected for the $\mathrm{Ni}-\mathrm{Cu}+$ Epoxy coating, which is not the case. In fact, the Ni-Cu-Epoxy coating is better attached than any other coating and unchanged by the heat treatments.

As expected, the pull-off strength of the 1-cycle epoxy is significantly lower than the other two. Actually, almost no epoxy was left on the magnets so these results should not be considered valid for epoxy.

\section{Corrosion test in salt spray chamber}

three magnets of each category was placed in the salt spray chamber, and their level of corrosion was monitored visually over time in accordance with the standard, DS/EN ISO 4628-3. The results for all the coatings are graphed in Figure 10 where the $y$-axis represents the severity of corrosion on a scale from 0 to 5 .

The rust levels of the epoxy coated magnets are increasing almost linearly, except for the 1-cycle epoxy, which rusted

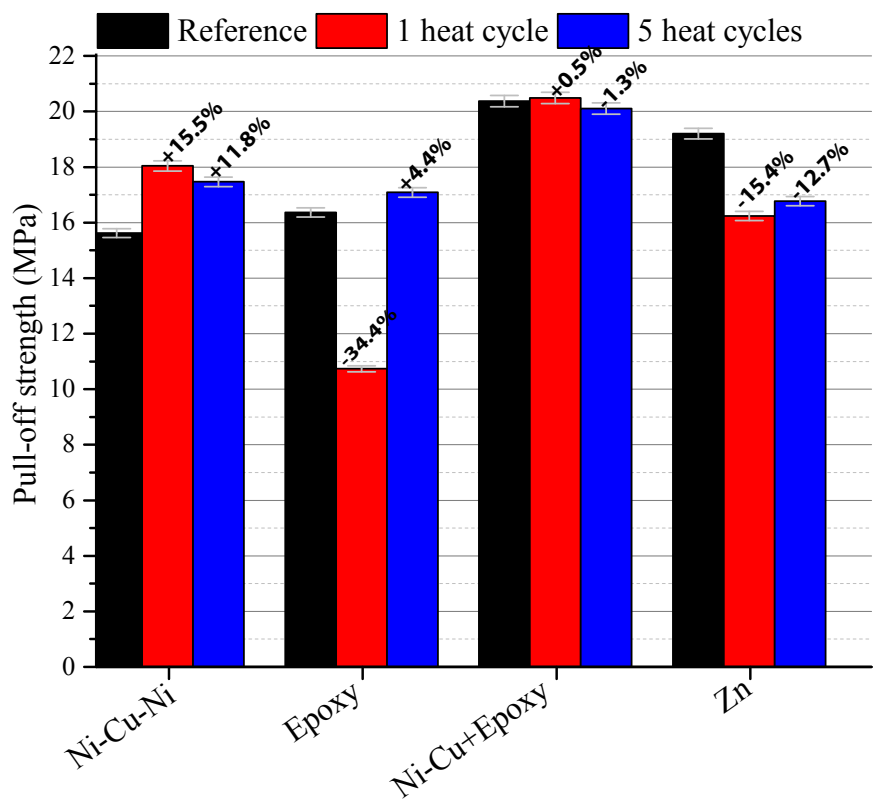

Fig. 9. Pull-off strength presented for the different coatings.

almost immediately, since the layer of epoxy probably evaporated at the high temperature. The 5-cycle rust faster then the reference, so it is clear that the Curie temperature has influenced the quality of the coating.

The $\mathrm{Zn}$ coated magnets show similar degradation with temperature. The 5-cycle $\mathrm{Zn}$ magnets are the worst, followed by the 1-cycle $\mathrm{Zn}$ magnets. It is worth noting that this coating rusts with almost a step function like trend, and all the $\mathrm{Zn}$ magnets, including the reference ones, rust faster than the epoxy coated magnets.

$\mathrm{Ni}-\mathrm{Cu}-\mathrm{Ni}$ is known for its excellent ability to protect the $\mathrm{Nd}-\mathrm{Fe}-\mathrm{B}$ magnet against corrosion, which is also observable here. All the coatings kept rust levels at 0 or 1 throughout the first 600 hours.

The Ni-Cu+Epoxy coated perform even better than the Ni$\mathrm{Cu}-\mathrm{Ni}$ coating, and all the magnets are intact after 2000 hours. A well known reason for rust to begin in $\mathrm{Ni}-\mathrm{Cu}-\mathrm{Ni}$ magnets is the so called pin-hole fractures which can exist in the coating. The holes are enough for the atmosphere to get in and begin the corrosion process. We believe that the epoxy layer on top of the Ni-Cu layers has the ability to seal off any of these pin-hole fractures.

\section{Microscopy inspection of coating/magnet interface}

Two different cross-sections of the magnets were investigated, as depicted to the left in Figure 7. The general conclusion was that all the coatings maintained visual integrity after heat treatments.

The microscopy investigation of the magnets aimed at revealing any visible defects in the coatings as a result of the heat treatments. As the left side of Figure 11 shows, almost the entire layer of epoxy had evaporated after the heat cycle of very high temperature. The right side of Figure 11 shows a still healthy $\mathrm{Ni}-\mathrm{Cu}+$ Epoxy coating after receiving five heat cycles. 

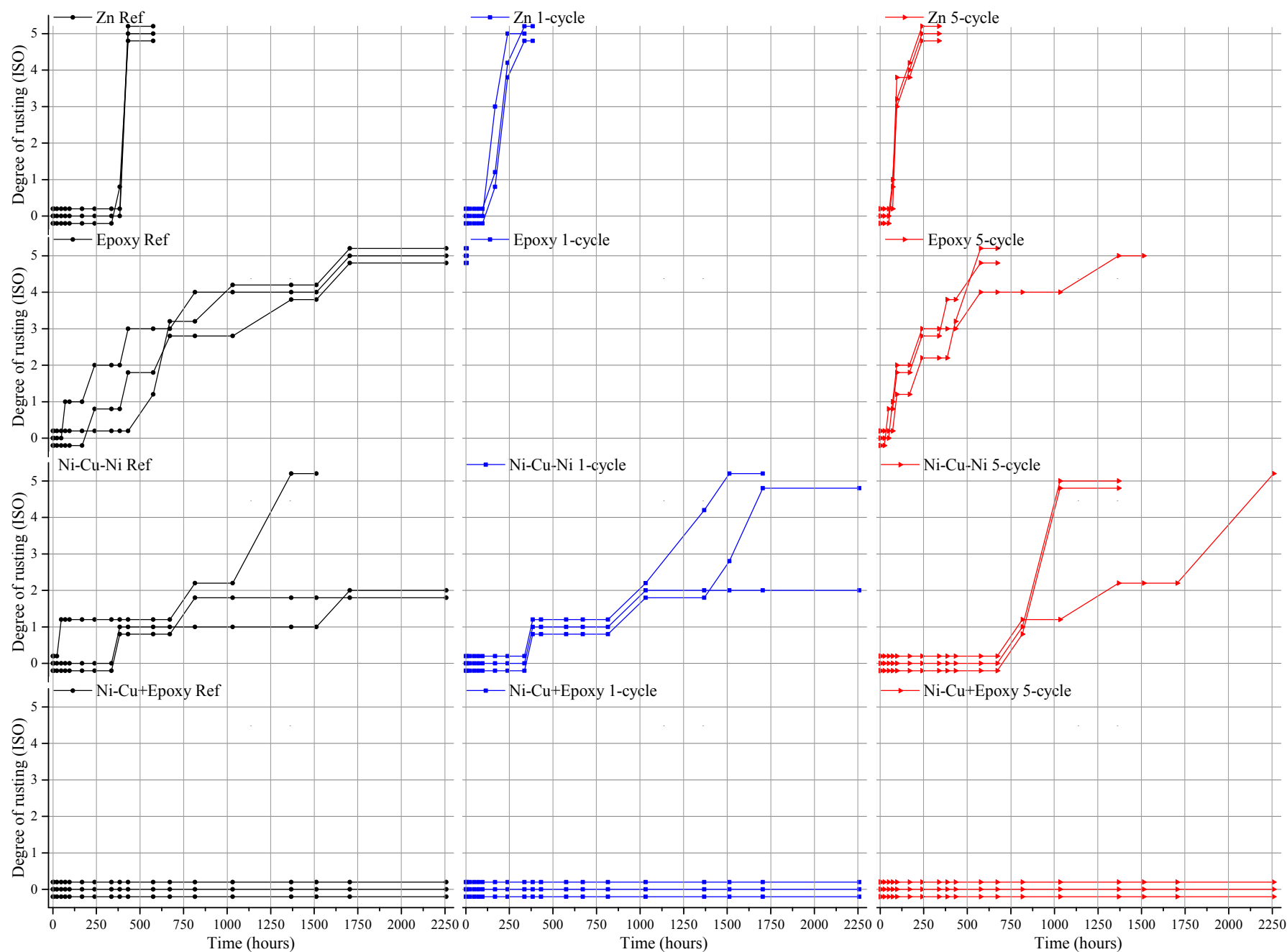

Fig. 10. Corrosion level of coated magnets in salt spray chamber over time. From the top and down: Zn, Epoxy, Ni-Cu-Ni, and Ni-Cu+Epoxy.
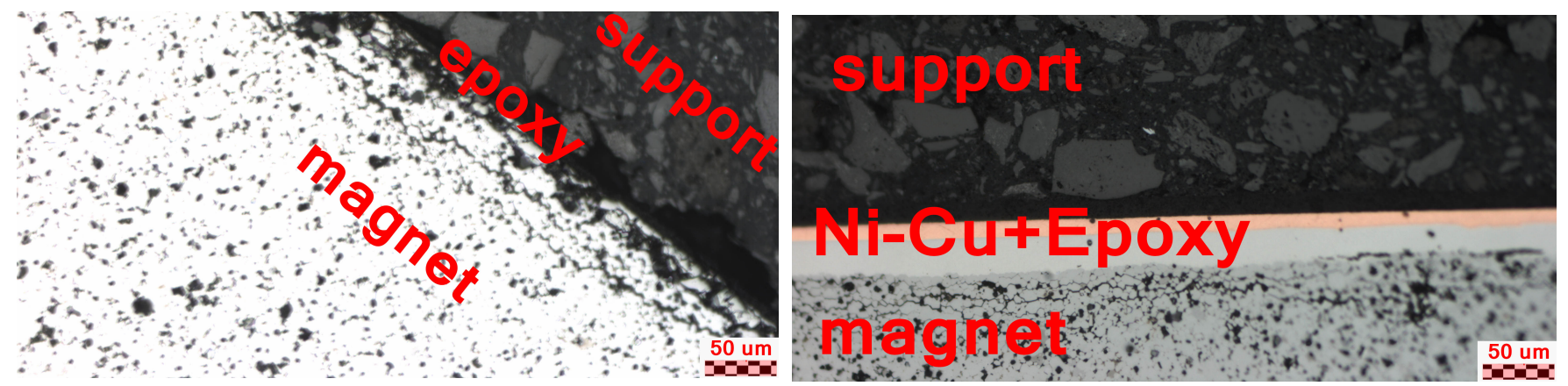

Fig. 11. Left: 1-cycle epoxy coated magnet, where almost no epoxy is left. Right: Ni-Cu+Epoxy coated magnet after 5 heat cycles. The coating still appears completely intact. The scale in the lower right corners is $50 \mu \mathrm{m}$.

However, magnet delamination for all batches (including reference) was encountered observing the side cross-section cut (clear cast of Figure 7). Examples of the delamination are shown in Figure 12. Since, the delamination is also present in all the reference magnets, the defect is either caused by the cast in process or by the manufacturing process. In any case, the explanation of this is outside the scope of this article, since it is unrelated to the heat treatments.

\section{E. Summary of the results}

In Table III, we have summarized the results from all the tests by giving each batch of magnets with individual coating a qualitative grade of 1 through 5 , where 1 is the worst grade and 5 is the best grade. The grades are given based on how well both the reference, the 1-cycle, and the 5-cycle magnets performed in the different tests. The final verdict in the last column repeats the lowest grade for each coating, since a 

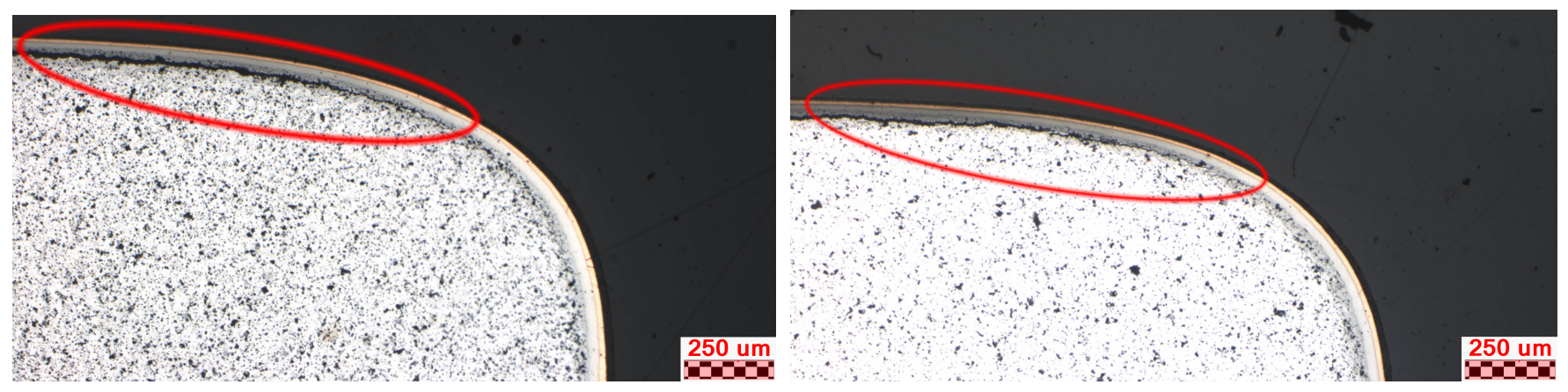

Fig. 12. Magnet delamination. Not between coating and magnet, but internally in the magnet. Here showing two cases of Ni-Cu+Epoxy. The scales in the lower right corners equal $250 \mu \mathrm{m}$.

magnet must perform equally well in all the categories in order to be suitable for the direct reuse strategy.

TABLE III

IN THIS TABLE, THE PERFORMANCE IS CONDENSED AND SUMMARIZED FOR ALL THE TESTS AND TYPES OF COATING. ITS QUALITATIVE GRADES ( 1 THROUGH 5, 1 BEING WORST, AND 5 BEING BEST) ARE GIVEN RELATIVE TO THE PERFORMANCE OF THE OTHER COATINGS.

\begin{tabular}{lcccc|c}
\hline Coating & $J-H$ & Pull-off & Salt spray & Microscopy & Verdict \\
\hline Epoxy & 5 & 3 & 1 & 5 & 1 \\
Zn & 5 & 3 & 2 & 5 & 2 \\
Ni-Cu-Ni & 5 & 5 & 4 & 5 & 4 \\
Ni-Cu+Epoxy & 5 & 5 & 5 & 5 & 5 \\
\hline
\end{tabular}

The very negative grades given to epoxy 1-cycle should of course be interpreted knowing that its heat treatment failed. That said, the overall performance of the epoxy coated magnets do not reach the levels of the rest. Nor is $\mathrm{Zn}$ a wise choice for implementing the direct reuse strategy. It was clear from the salt spray test that the $\mathrm{Zn}$ coating suffers during the heat treatments. However, the reference batch of $\mathrm{Zn}$ coated magnets did not perform well either. Both $\mathrm{Ni}-\mathrm{Cu}-\mathrm{Ni}$ and $\mathrm{Ni}$ $\mathrm{Cu}$-Epoxy coated magnets performed outstandingly in all the tests. However, the Ni-Cu+Epoxy coated magnets revealed a big advantage from the salt spray tests results. The Epoxy layer seems to seal off any pin-hole fractures the $\mathrm{Ni}-\mathrm{Cu}$ layer might have, and effectively prolongs the lifetime of the magnets.

\section{CONCLUSIONS}

To which extent magnets with four different coatings were affected by a recycling process that necessitates exposure to the Curie temperature of approximately $350^{\circ} \mathrm{C}$ was investigated in this article. One batch was kept untreated and served as a reference, one batch received one cycle of Curie temperature, and one batch received 5 cycles of the Curie temperature. All heat treatments were caried out in a nitrogen protective atmosphere to avoid oxidation of the coatings or magnets. Each of the four coatings, Epoxy, $\mathrm{Zn}, \mathrm{Ni}-\mathrm{Cu}-\mathrm{Ni}$, and $\mathrm{Ni}-\mathrm{Cu}+$ Epoxy, were evaluated based on their performance in the four different tests: J-H measurements to evaluate their magnetic performance, coating pull-off test to evaluate how well the coating is attached to the magnet, salt spray test to evaluate how well the coating protects against corrosion, and finally microscopic inspection of the interface between magnet and coating in order to determine defects caused by the heat treatments.

The magnetic performance of magnets heat treated once or five times remained comparable to that of the reference magnets. Nor was any significant loss observed from the coating pull-off tests. However, $\mathrm{Ni}-\mathrm{Cu}-\mathrm{Ni}$ and $\mathrm{Ni}-\mathrm{Cu}+\mathrm{Epoxy}$ performed somewhat better than the rest. The performance of the different coating varied widely in the salt spray test. The results suggest that the epoxy coating did not offer a good protection against corrosion, and this was only worsened with the heat treatments. This was even worse for the $\mathrm{Zn}$ coating which reached category 5 rust level faster than any of the other coatings. Both $\mathrm{Ni}-\mathrm{Cu}-\mathrm{Ni}$ and $\mathrm{Ni}-\mathrm{Cu}+$ Epoxy were great at offering corrosion resistance, but after more than 1500 hours only the Ni-C+Epoxy coating was still showing no signs of corrosion. We believe that the epoxy layer on top of the $\mathrm{Ni}-\mathrm{Cu}$ layers have a sealing effect on the pin-hole fractures sometimes encountered in $\mathrm{Ni}-\mathrm{Cu}-\mathrm{Ni}$ coated magnets, which are the main source to corrosion.

The results presented in this article suggest that it is possible to reuse magnets directly by properly selecting the coating. Ni$\mathrm{Cu}+$ Epoxy proved to be an excellent choice for direct reuse, but several other coatings exist, which were not tested here.

\section{REFERENCES}

[1] C. Li, W. Liu, m. yue, Y. Liu, D. Zhang, and T. Zuo. Waste Nd-Fe-B sintered magnet recycling by doping with rare earth rich alloys. IEEE Transactions on Magnetics, Early Access Online, 2014.

[2] R.S. Sheridan, A.J. Williams, I.R. Harris, and A. Walton. Improved HDDR processing route for production of anisotropic powder from sintered $\mathrm{NdFeB}$ type magnets. Journal of Magnetism and Magnetic Materials, 350:114118, January 2014.

[3] Chins Chinnasamy, Melania Marinescu Jasinski, Peter Dent, and Jinfang Liu. Cost effective recycling process of industrial scrap and hard drive scrap rare earth magnets into valuable permanent magnets. In Advances in Powder Metallurgy and Particulate Materials, pages 7139-7147, 2013.

[4] Oliver Gutfleisch, Konrad Güth, Thomas George Woodcock, and Ludwig Schultz. Recycling used Nd-Fe-B 
sintered magnets via a Hydrogen-Based route to produce anisotropic, resin bonded magnets. Advanced Energy Materials, 3(2):151-155, 2013.

[5] R.S. Sheridan, R. Sillitoe, M. Zakotnik, I.R. Harris, and A.J. Williams. Anisotropic powder from sintered $\mathrm{NdFeB}$ magnets by the HDDR processing route. Journal of Magnetism and Magnetic Materials, 324(1):63-67, January 2012.

[6] E. A. Perigo, S. C. da Silva, R. V. Martin, H. Takiishi, and F. J. G. Landgraf. Properties of hydrogenationdisproportionation-desorption-recombination $\quad \mathrm{NdFeB}$ powders prepared from recycled sintered magnets. Journal of Applied Physics, 111(7), 2012.

[7] M. Zakotnik, D. Prosperi, and A.J. Williams. Kinetic studies of hydrogen desorption in SmCo 2/17-type sintered magnets. Thermochimica Acta, 486(1-2):41-45, March 2009.

[8] M. Zakotnik, I.R. Harris, and A.J. Williams. Possible methods of recycling NdFeB-type sintered magnets using the HD/degassing process. Journal of Alloys and Compounds, 450(1-2):525-531, February 2008.

[9] Masahiro Itoh, Masahiro Masuda, Shunji Suzuki, and Ken-ichi Machida. Recycling of rare earth sintered magnets as isotropic bonded magnets by melt-spinning. Journal of Alloys and Compounds, 374(12):393-396, July 2004.

[10] A. S. Kim, D. H. Kim, S. Namkung, T.S. Jang, D. H. Lee, H.W. Kwon, and D. H. Hwang. Development of high coercive powder from the Nd-Fe-B sintered magnet scrap. IEEE Transactions on Magnetics, 40(4):28772879, 2004.

[11] Stig Högberg, Nenad Mijatovic, Bogi Bech Jensen, Flemming Buus Bendixen, and Joachim Holbøll. Direct reuse of rare earth permanent magnets - wind turbine generator case study. In XXVIh International Conference on Electrical Machines (ICEM), 2016.

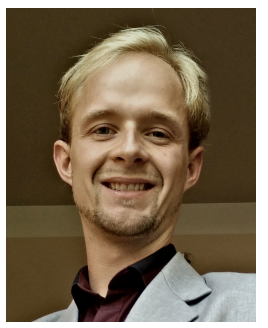

Stig Högberg is since 2012 a Ph.D. researcher at the department of electrical engineering, Technical University of Denmark (DTU). He received his B.Sc. and M.Sc. degrees in electrical engineering in 2009 and 2012, respectively from DTU, and has since been teaching electrical machinery at different universities. As part of REEgain innovation consortium, S. Högberg's research pertains to recycling-friendly electrical machine design, with focus on rare-earth permanent magnets in wind turbine generators and electric vehicle motors.

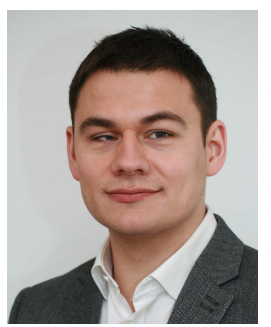

Bogi Bech Jensen Bogi Bech Jensen is Rector of Glasir, Torshavn College, Faroe Islands. $\mathrm{He}$ is also professor of energy engineering at the University of the Faroe Islands and visiting professor at Newcastle University, UK. He received his doctorate from Newcastle University, UK, where he also held positions as research associate and lecturer. $\mathrm{He}$ was associate professor and later Head of Research Group at the Department of Electrical Engineering, Technical University of Denmark (DTU), where he won the Best Teacher Award Spring 2011. In 2013 he won the AEG Electron Award, which is awarded once a year to an outstanding researcher in Denmark. Professor Jensen has more than 80 peerreviewed scientific publications, mainly in the field of electrical machines. He is a senior member of IEEE and was associate editor of IEEE Transactions on Industry Applications from 2011 till 2015.

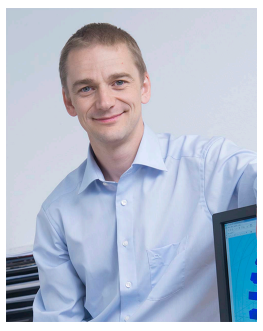

Flemming Buus Bendixen received his M.Sc.E.E. in 1997 and his Ph.D. in 2006 within motor-design and control. He has worked with motor-design and magnetic materials for Grundfos a/s, inverter-design and motor-control for Vestas a/s, and currently he is a senior magnet specialist for Sintex a/s. He has filed more than 13 different patent applications.

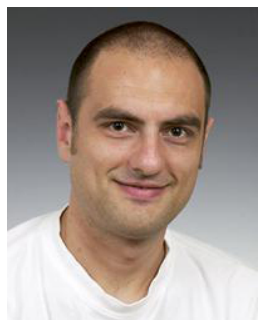

Nenad Mijatovic received his Ph.D. degree from Technical University of Denmark for his work with superconducting machines. After obtaining his Dipl.Ing. education at University of Belgrade, Serbia, he enrolled as a doctoral candidate at Technical University of Denmark in 2012 working on technical feasibility of superconducting machine in wind industry. Upon completion of his $\mathrm{PhD}$, he continued work in the same field as an Industrial PostDoc. Dr. N. Mijatovic currently holds a position of Associate Professor at Technical University of Denmark where he is in charge of managing research projects and education related to the field of electrical machines and drives, motion control, low frequency magnetism in general and large scale application of superconductivity. He is a member of IEEE since 2008 and his field of interest and research includes novel electrical machine/actuator designs, operation, control and diagnostic of electromagnetic assemblies.

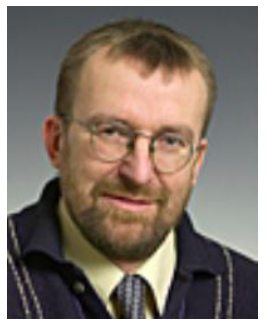

Joachim Holbøll Holbøll is associate professor and deputy head of center at DTU, Department of Electrical Engineering, Center for Electric Power and Energy. His main field of research is high voltage components, their properties, condition and broad band performance, including insulation systems performance under AC, DC and transients. Focus is also on wind turbine technology and future power grid applications of components. J. Holbøll is Senior Member of IEEE. 